\title{
Dynamic Stochastic Factors, Risk Management and the Energy Futures
}

\author{
Zi-Yi Guo ${ }^{1}$, Yangxiaoteng Luo $^{2}$ \\ ${ }^{1}$ Corporate Model Risk Management Group, Wells Fargo Bank, N.A., 301 S College St, Charlotte, NC 28202, \\ USA \\ ${ }^{2}$ Yangxiaoteng Luo, Kellstadt Graduate School of Business, Depaul University, 1 E Jackson Blvd, Chicago, IL \\ 60604, USA \\ Correspondence: Zi-Yi Guo, Corporate Model Risk Management Group, Wells Fargo Bank, N.A., 301 S College \\ St, Charlotte, NC 28202, USA. \\ All views are those of the author and do not necessarily reflect those of the organization to which the author is \\ affiliated.
}

Received: June 30, 2017

doi:10.5539/ibr.v10n9p50
Accepted: July 31, $2017 \quad$ Online Published: August 1,2017

URL: https://doi.org/10.5539/ibr.v10n9p50

\begin{abstract}
The world crude oil prices have dropped dramatically, and consequently the oil market has become very volatile and risky in the last several years. Since energy markets play very important roles in the international economy and have led several global economic crises, risk management of energy products prices becomes very important for both academicians and market participants. Schwartz and Smith's model (2000) is applied to calculate risk measures of Brent oil futures contracts and light sweet crude oil (WTI) futures contracts. The model includes a long-term factor and a short-term factor. We show that the two factors explain the Samuelson effect well and the model present well goodness of fit. Our back testing results demonstrate that the models provide satisfactory risk measures for listed crude oil futures contracts.
\end{abstract}

\section{JEL classifications: C58; G13; G32}

Keywords: factor model; value-at-risk; exceedances

\section{Introduction}

The world crude oil prices have dropped dramatically, and consequently the oil market has become very volatile and risky in the last several years. Moreover, energy markets play very important roles in the international economy and have led several global economic crises, for example the 1973 oil crisis. Therefore, risk management of energy products prices becomes very important for both academicians and market participants, and many risk measurement tools have been proposed in the literature. A non-exhausted list includes: Cabedo and Moya (2003), Costello, Asem and Gardner (2008), Krehbiel and Adkins (2005), Marimoutou, Raggad and Trabelsi (2009), Kang and Yoon (2013), Youssef, Belkacem, and Mokni (2015), and Fiano and Grossi (2015). These papers employ a widely-used risk measure, Value-at-Risk (VaR) originally proposed by J.P. Morgan in 1994 (see Duffie and Pan, 1997, for a discussion of this measure), but differ in the model assumptions. Nevertheless, all the above literature employs a reduced-form approach and calculates VaRs directly from modeling prices returns (for example, fitting the entire returns samples into a certain distribution, or the tail returns samples into the extreme value distributions), and thus the models cannot provide useful information about the spot or the futures price fluctuations.

Recently, stochastic models of commodity futures prices have been frequently employed in modeling commodity-related securities among academics and practitioners, such as Schwartz (1997), Schwartz and Smith (2000), Sorensen (2002), Cortazar and Schwartz (2003), Mirantes, Poblacion and Serna (2012), Carmona and Coulon (2014), and et al.. A detailed survey of these types of models is written by Pirrong (2011). Most of the papers employ the stochastic multi-factor models for explaining futures prices fluctuations, and not directly from a risk management perspective. In this paper, we illustrate that by employing the Monte Carlo methods the stochastic multi-factor models are also powerful in calculating risk measures, such as Value at Risk or expected shortfall. Compared with other approaches focusing on either cash contract or one single future contract, our 
approach has the advantage in calculating the VaRs for the whole forward curve simultaneously. By assuming the forward curve is driven by several core factors, our approach could account for intrinsic correlations among contracts with different tenors without using other tools, such as multivariate distributions or copulas which are commonly used to model the correlations of multi-variables in the literature.

Our model is a two-factor model. The model has become a benchmark for modeling the stochastic behavior of crude oil futures prices. The multi-factor models evaluate futures prices as risk-adjusted expected values of spot price and assume that the spot price is sum of the short- and the long-term components. To model the long-term price dynamics the long-term factor is assumed to evolve according to geometric Brownian motion, and the drift of the model reflects expectations of the exhaustion of existing supply, improving technology for the production and the discovery of the commodity, inflation, as well as political and regulatory effects. To model the short-term price deviation to its long-term dynamics, the short-term factor is assumed to follow a mean-reverting process and reflects short-term changes in demand or supply, for instance, resulting from variations in the weather or intermittent supply disruptions. In this paper, we show that Schwartz and Smith's model could provide satisfactory risk measures for Brent crude oil futures and light sweet crude oil futures.

The remainder of the paper is organized as follows. Section 2 describes the futures data and several stylized facts of the data. In Section 3, we introduce Schwartz and Smith's model. The estimation method and results are in Section 4. In Section 5, we summarize the backtesting results of the two models. Section 6 concludes.

\section{Empirical Data Analysis}

In this section, we briefly summarize the basic features of futures price data and show the a stylized fact, the Samuelson effect, for all the commodities. We collect futures price data from Bloomberg for Brent crude oil and light sweet crude oil (WTI). The time periods span from February 14, 2005 to March 28, 2014 for Brent crude oil and from February 23, 2005 to March 11, 2014 for light sweet crude oil (WTI). All the time periods reflect the longest time periods available for the authors. The descriptive statistics of the data is provided in Table 1.

Table 1. Descriptive statistics of futures prices for all the eight commodities.

\begin{tabular}{|c|c|c|c|c|}
\hline Commodity & Observations & Mean & Standard Deviation & Unit \\
\hline B rent crude oil & 141399 & 86.73 & 18.07 & dollars per barrel \\
\hline WTI & 152262 & 83.96 & 15.46 & dollars per barrel \\
\hline
\end{tabular}

Table 2-3 provides detailed summary statistics with respect to the involved futures contracts for the eight commodities respectively. We group futures prices according two criteria: grouped into expiration months and grouped into time to maturity. The futures contracts for all the eight commodities have twelve expiration months, and in Panel A of all the tables we present the summary results for futures contracts maturing in the odd months. In Panel B of all the tables we present the summary results for futures contracts grouped into time to maturity. The terminology "1.closest maturity" is used as notation for the futures contracts that have the shortest time to maturity at a given date; the "2.closest maturity" represents the futures contract with the second shortest time to maturity; and so on. To illustrate futures price fluctuations, we calculate futures returns as log returns of the time series. The tables indicate at least one basic feature of futures prices of the two commodities that the variations of distant maturity futures prices and futures returns are lower than nearby futures prices and futures returns - the Samuelson effect.

Samuelson (1965) first investigates the relationship between futures price volatility and contract maturity and proposes the hypothesis that the volatility of futures price changes should increase as the delivery date nears. To exclude the case that the small standard deviations for the longest maturities to some extent merely reflect that the data for these contracts are sampled only over short continuous time periods, we compare the maturities which have the same number of observations. In Panel Bs of Table 2-3, we see the Samuelson effect not only of futures price volatility but also of futures return volatility for all the commodities.

Figure 1 and 2 further illustrate the time series aspects of the data. The figures graph the time-series of futures prices and futures returns for the 1.closest maturity and the 23.closest maturity. The 1.closest maturity and the 23.closest maturity represent the contract series maturing next month and right after two years respectively. A visual inspection of the figures suggests that the time series for the 1.closest maturity is more volatile than the 23.closest maturity time series. Again, this is in line with the "Samuelson hypothesis". This feature of the energy commodity futures prices will be captured in Schwartz and Smith's model by including a mean-reverting component. 
Table 2. Summary Statistics for Brent Crude Oil Futures. Futures prices are in dollars per barrel. The dataset consists of 2350 daily observations from $02 / 14 / 2005$ to $03 / 28 / 2014$

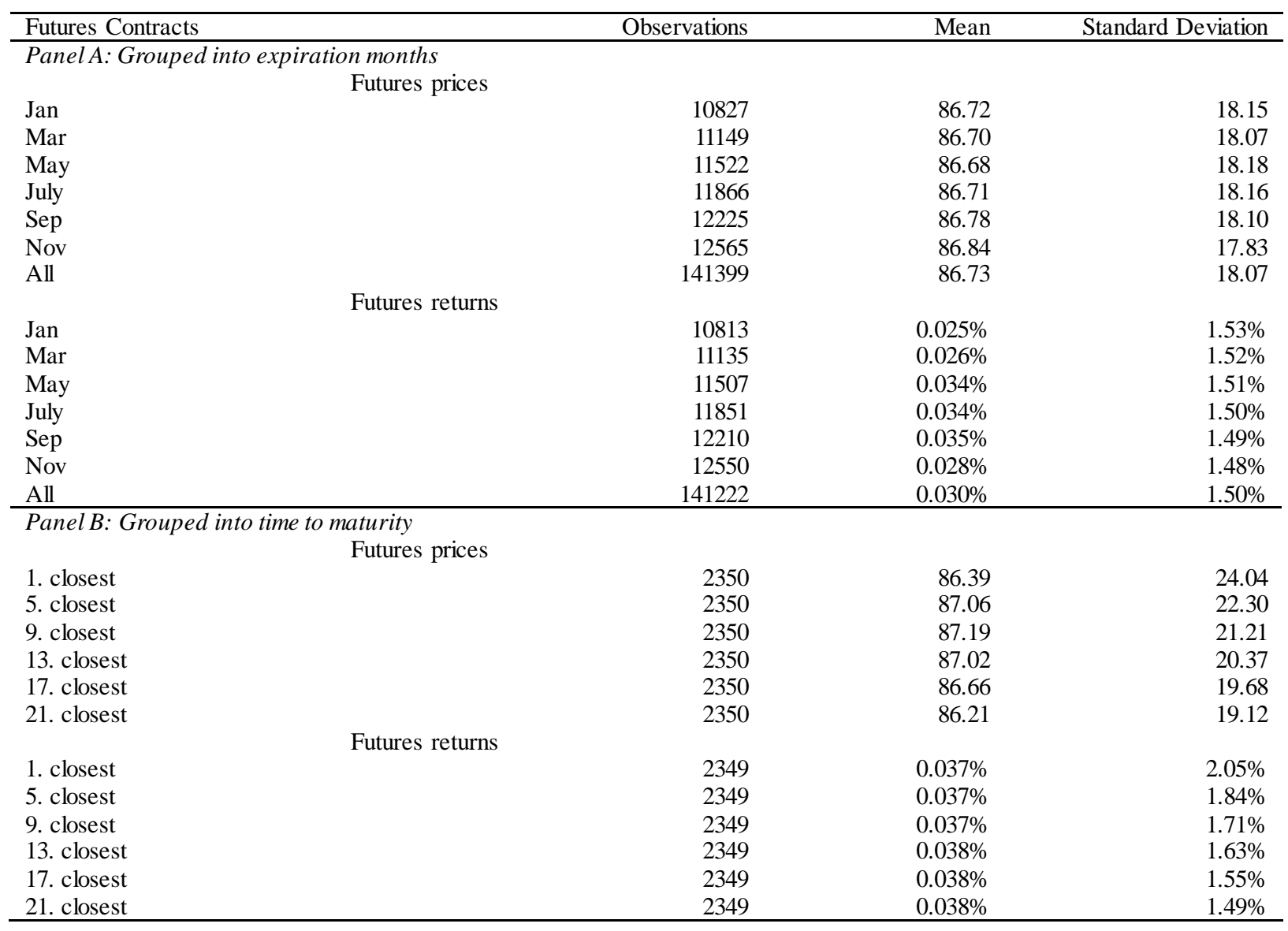


Figure 1. Futures prices with different time to maturity 
Table 3. Summary Statistics for Light Sweet Crude Oil (WTI) Futures. Futures prices are in dollars per barrel. The dataset consists of 2278 daily observations from $02 / 23 / 2005$ to $03 / 11 / 2014$

\begin{tabular}{|c|c|c|c|}
\hline Futures Contracts & Observations & Mean & Standard Deviation \\
\hline \multicolumn{4}{|c|}{ Panel A: Grouped into expiration months } \\
\hline \multicolumn{4}{|c|}{ 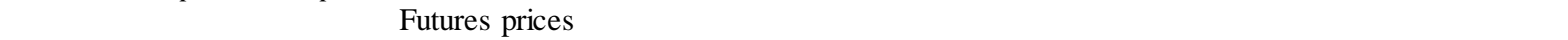 } \\
\hline Jan & 10911 & 83.84 & 15.27 \\
\hline Mar & 11283 & 83.68 & 15.29 \\
\hline May & 11604 & 83.73 & 15.34 \\
\hline July & 11933 & 83.81 & 15.43 \\
\hline Sep & 12317 & 83.86 & 15.47 \\
\hline Nov & 12637 & 84.01 & 15.19 \\
\hline \multirow{2}{*}{\multicolumn{4}{|c|}{ Futures returns }} \\
\hline & & & \\
\hline Jan & 10897 & $0.011 \%$ & $1.59 \%$ \\
\hline Mar & 11269 & $0.015 \%$ & $1.59 \%$ \\
\hline May & 11589 & $0.021 \%$ & $1.57 \%$ \\
\hline July & 11918 & $0.022 \%$ & $1.55 \%$ \\
\hline Sep & 12302 & $0.023 \%$ & $1.54 \%$ \\
\hline Nov & 12622 & $0.017 \%$ & $1.54 \%$ \\
\hline All & 152085 & $0.020 \%$ & $1.56 \%$ \\
\hline \multicolumn{4}{|c|}{ Panel B: Grouped into time to maturity } \\
\hline & & & \\
\hline 1. closest & 2278 & 81.37 & 19.81 \\
\hline 5. closest & 2278 & 83.05 & 18.32 \\
\hline 9. closest & 2278 & 83.43 & 17.52 \\
\hline 13. closest & 2278 & 83.41 & 16.91 \\
\hline 17. closest & 2278 & 83.18 & 16.42 \\
\hline \multirow[t]{2}{*}{ 21. closest } & 2278 & 82.89 & 16.10 \\
\hline & & & \\
\hline 1. closest & 2277 & $0.029 \%$ & $2.34 \%$ \\
\hline 5. closest & 2277 & $0.028 \%$ & $1.95 \%$ \\
\hline 9. closest & 2277 & $0.029 \%$ & $1.81 \%$ \\
\hline 13. closest & 2277 & $0.029 \%$ & $1.71 \%$ \\
\hline 17. closest & 2277 & $0.029 \%$ & $1.63 \%$ \\
\hline 21. closest & 2277 & $0.029 \%$ & $1.57 \%$ \\
\hline
\end{tabular}
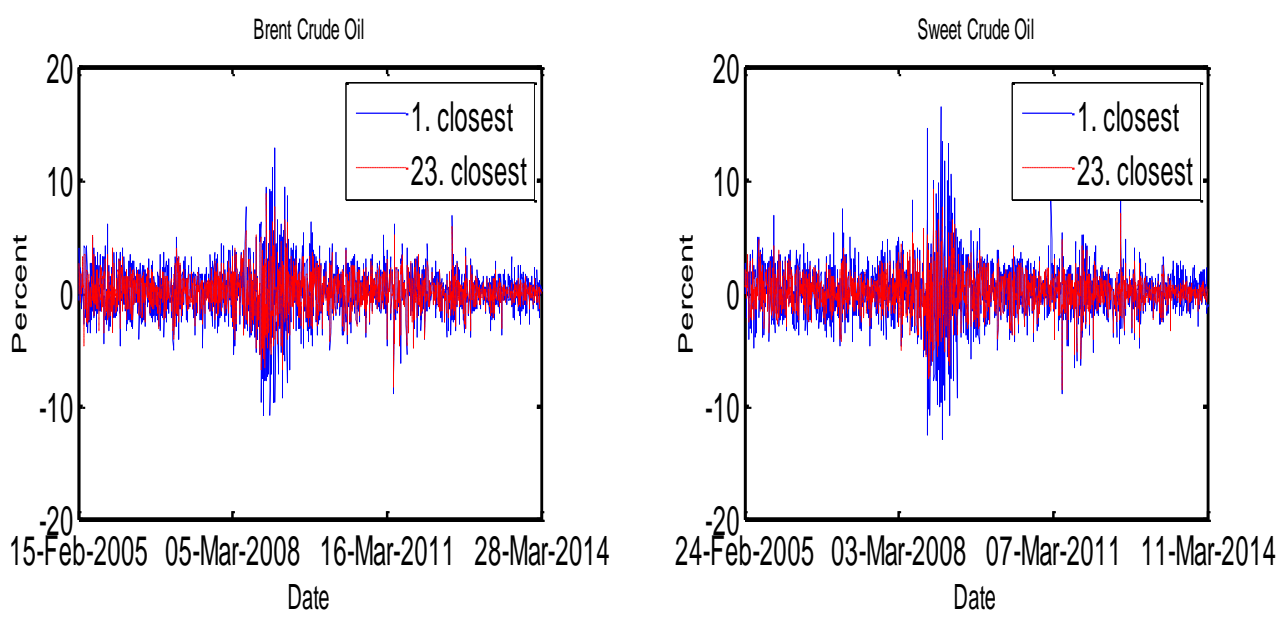

Figure 2. Futures returns with different time to maturity

\section{The Models}

In this section, we present Schwartz and Smith's model (2000) for Brent crude oil futures and light sweet crude oil futures (WTI).

Schwartz and Smith's model assumes that spot prices consist of two stochastic factors and calculates futures prices as the risk-adjusted expected value of spot prices. The logarithm of the spot price $p_{t}=\ln \left(P_{t}\right)$ is given by $p_{t}=x_{t}+z_{t}$, where $x_{t}$ denotes the long-term equilibrium price level and $z_{t}$ the short-term deviation in prices. The equilibrium level $x_{t}$ follows a non-stationary process 


$$
d x_{t}=\left(\mu-\frac{\sigma_{x}^{2}}{2}\right) d t+\sigma_{x} d w_{x t},
$$

and the short-term deviation $z_{t}$ follows a mean-reverting process

$$
d z_{t}=-\kappa z_{t} d t+\sigma_{z} d w_{z t} .
$$

Both $d w_{x t}$ and $d w_{z t}$ are standard Brownian motion processes with constant correlation coefficient $\rho$, and it is assumed that the standard filtration generated by the two-dimensional $\left(w_{x t}, w_{z t}\right)$ describes all the information available in the economy. $\sigma_{x}$ and $\sigma_{z}$ indicate volatilities of the innovations.

Under the so called equivalent martingale measure, which is relevant for pricing and denoted here by $Q$, the dynamics of the two factors $x_{t}$ and $z_{t}$ are described by

$$
d x_{t}=\left(\alpha-\frac{\sigma_{x}^{2}}{2}\right) d t+\sigma_{x} d w_{x t} Q
$$

and

$$
d z_{t}=-\left(\lambda_{z}+\kappa z_{t}\right) d t+\sigma_{z} d w_{z t} Q
$$

where $\alpha=\mu-\lambda_{x}$, and $\lambda_{x}$ and $\lambda_{\tilde{z}}$ are constant market prices of risk associated with $x_{t}$ and $z_{t}$, respectively. Moreover, $w_{x t}{ }^{x}$ and $w_{z t}{ }^{\mathcal{L}}$ describes the martingale under $Q$. Let $F_{t}(\tau)$ denotes the future price at time $t$ on a futures contract that expires at time $\tau$. By taking the relevant expectations,

$$
F_{t}(\tau)=\exp \left(x_{t}+z_{t} e^{-\kappa(\tau-t)}+A_{1}(\tau-t)\right)
$$

where $\quad A_{1}(T)=b_{1}\left(1-e^{-2 \kappa T}\right)+b_{2}\left(1-e^{-\kappa T}\right)+b_{3} T \quad, \quad$ and $\quad b_{1}=\frac{\sigma_{z}^{2}}{2 \kappa} \quad, \quad b_{2}=-\frac{\lambda_{z}-\rho \sigma_{x} \sigma_{z}}{\kappa} \quad$,and $b_{3}=\mu-\lambda_{x}$. Here the logarithm of the futures prices is an affine function of the two factors $x_{t}$ and $z_{t}$. Since our interest is in risk management of futures contracts, it is sufficient to only estimate $\kappa, b_{1}, b_{2}$, and $b_{3}$ and leave other parameters unknown in our application.

\section{Model Estimation}

We write the above model in a discrete state-space form. The state space representation consists of a transition equation and a measurement equation. The transition equation describes the stochastic evolvement of an unobserved vector of state-variables, and the measurement equation relates the unobserved state-variables to a vector of observables. We sample the data at equidistant time points $t_{n}, n=1, \ldots, N$ and in this paper $\Delta=t_{n+1}-t_{n}$ denotes one day.

Let $X_{n}=\left(x_{t_{n}}, z_{t_{n}}\right)^{\prime}$ denote the unobserved state-vector at time $t_{n}$. Formally, the transition equation has the following form:

$$
X_{n+1}=a+A X_{n}+\eta_{n}
$$


where $\eta_{n}, n=1, \ldots, N$ are serially uncorrelated with zero mean-vector and covariance matrix $\sum_{2 \times 2}$ and

$$
a=\left(\begin{array}{c}
\left(\mu-\frac{\sigma_{x}^{2}}{2}\right) \Delta \\
0
\end{array}\right) \text { and } A=\left(\begin{array}{cc}
1 & 0 \\
0 & e^{-\kappa \Delta}
\end{array}\right) .
$$

We define $b_{4} @ \mu-\frac{\sigma_{x}^{2}}{2}$. Let $f_{t}(\tau)=\log F_{t}(\tau)$ and $Z_{n}=\left(f_{t_{n}}\left(\tau_{n}{ }^{1}\right), \ldots, f_{t_{n}}\left(\tau_{n}{ }^{M_{n}}\right)\right)^{\prime}$ denote the set of $\log$ futures prices observed at time $t_{n}$ and with maturities $\tau_{n}{ }^{1}<\tau_{n}{ }^{2}<\ldots<\tau_{n}{ }^{M_{n}}$. The measurement equation has the following form:

$$
Z_{n}=c_{n}+C_{n} X_{n}+\varepsilon_{n}
$$

where $\varepsilon_{n}, n=1, \ldots, N$ are serially independently distributed with zero mean-vector and covariance matrix

$$
H_{M_{n} \times M_{n}}
$$

$$
c_{n}=\left(\begin{array}{c}
A_{1}\left(\tau_{n}{ }^{1}-t_{n}\right) \\
\mathrm{M} \\
A_{1}\left(\tau_{n}^{M_{n}}-t_{n}\right)
\end{array}\right) \text {, and } C_{n}=\left(\begin{array}{cc}
1 & e^{-\kappa\left(\tau_{n}^{1}-t_{n}\right)} \\
\mathrm{M} & \mathrm{M} \\
1 & e^{-\kappa\left(\tau_{n} M_{n}-t_{n}\right)}
\end{array}\right) \text {. }
$$

The estimation method is essentially a two-step least square estimation method. The minimization problem can be expressed as

$$
\min _{\left\{\kappa, b_{1}, b_{2}, b_{3}, b_{4}\right\}} \sum_{n=1}^{N}\left[\left(x_{t_{n}}-b_{4} \Delta-x_{t_{n-1}}\right)^{2}+\left(z_{t_{n}}-e^{-\kappa \Delta} z_{t_{n-1}}\right)^{2}\right]
$$

s.t.

$$
\left\{x_{t_{n}}, z_{t_{n}}\right\} \in \underset{x_{t_{n}}, z_{t_{n}}}{\arg \min } \sum_{i=1}^{M_{n}}\left[f_{t_{n}}\left(\tau_{n}{ }^{i}\right)-x_{t_{n}}-z_{t_{n}} e^{-\kappa\left(\tau_{n}{ }^{i}-t_{n}\right)}-b_{1}\left(1-e^{-2 \kappa\left(\tau_{n}{ }^{i}-t_{n}\right)}\right)-b_{2}\left(1-e^{-\kappa\left(\tau_{n}{ }^{i}-t_{n}\right)}\right)-b_{3}\left(\tau_{n}{ }^{i}-t_{n}\right)\right]^{2} .
$$

In implementation, one could calculate vector $X_{n}$ through the constraint condition first as

$$
X_{n}=\left(C_{n}{ }^{\prime} * C_{n}\right)^{-1}\left[C_{n}{ }^{\prime} *\left(Z_{n}-c_{n}\right)\right]
$$

Then, we plug the vector $X_{n}$ into (4.3) to solve the global minimization. Our method differs from Cortazar and Schwartz mainly through the constraint condition. In Cortazar and Schwartz, the vector $X_{n}$ is calculated through the transition equation, Equation (4.1), while our method calculates the vector $X_{n}$ through the forward curve, Equation (3.5), at time $n$. Our practice indicates minimizing Equation (3.5) instead of Equation (4.1) improves numerical stability and quick convergence. 


\section{Estimation Results}

\subsection{Estimation Results of the Whole Sample}

Table 4. Models estimation results. * and ** denote statistic significant at the 5\% and $1 \%$ level respectively

\begin{tabular}{lrr}
\hline & Brent Oil & WTI \\
\hline obs. & 141399 & 152262 \\
$b_{1}$ & $0.306^{* *}$ & $0.132^{* *}$ \\
$b_{2}$ & $-0.350^{* * *}$ & $-0.144^{* *}$ \\
$b_{3}$ & $0.010^{* *}$ & $0.004^{*}$ \\
$b_{6}$ & $0.099^{* *}$ & $0.075^{* *}$ \\
$\kappa$ & $0.541^{* *}$ & $0.468^{* *}$ \\
Std. of prices & 0.214 & 0.185 \\
RMSE & 0.010 & 0.012 \\
\hline
\end{tabular}

In this section, we first estimate our model by using the whole sample. Our estimation uses daily observations

and thus $\Delta=1 / 252$. The parameters estimations are in Table 4 . We plot the demeaned estimated two factors in

Figure 3. The correlation coefficients of the two factors of all the eight commodities are small positive numbers, ranging from 0.10 to 0.30 . In Table 4 , we also summarize the errors in the model fit for futures prices. In general, the models perform well in explaining futures price variations. The model explains around $95.3 \%$ and $93.5 \%$ of futures price variations for Brent Oil and WTI futures price variations respectively.
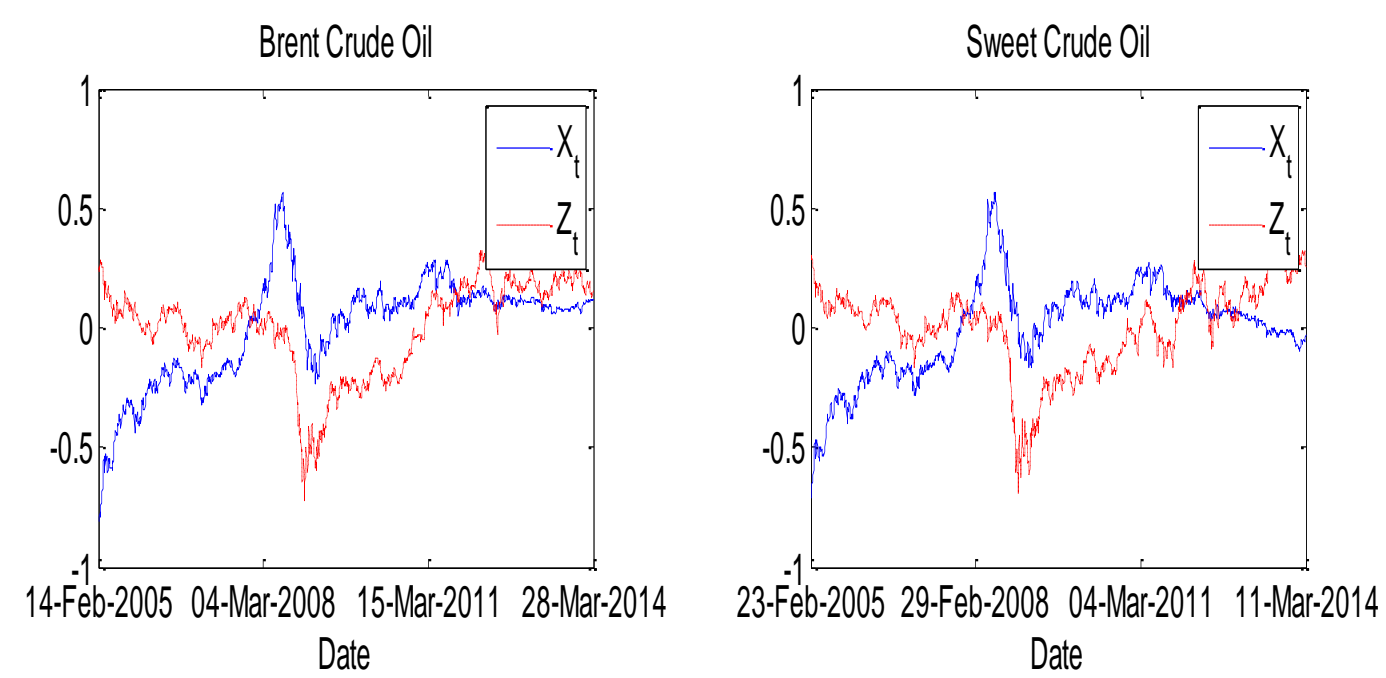

Figure 3. Latent factors $-\mathrm{Xt}$ and $\mathrm{Zt}$ (demeaned)

\subsection{Backtesting}

To backtest the model, we employ a rolling 500-day period to estimate the model and calculate risk measures: Value at Risk (VaR) and expected shortfall (ES). The choice of a rolling approximate two-year period is simply to avoid potential structural shifts of the parameters. To simplify the analysis, we fix the parameter $\kappa$ by the value in last section and estimate other parameters daily. The model is estimated consistently, there are no big jumps for the estimated parameters from day to day and the range of attainable values is relatively narrow.

We employ a Monte Carlo simulation to calculate the risk measures for a two-day horizon ${ }^{1}$. The Monte Carlo simulation of energy futures contracts requires two types of shocks: shocks from the transition equation $\eta_{n+1}$ and $\eta_{n+2}$ and shocks from the measurement equation $\varepsilon_{n+1}$ and $\varepsilon_{n+2}$. We randomly draw numbers from the multi-variable normal distribution for the shocks $\eta_{n+1}, \eta_{n+2}, \varepsilon_{n+1}$ and $\varepsilon_{n+2}$ to simulate scenarios of the two-day moves of the two factors $x_{n+2}$ and $z_{n+2}$. For each of the 10000 variable pairs, a theoretical price

\footnotetext{
${ }^{1}$ The two-day horizon simply reflects the practice of some clearing houses, for instance the Options Clearing Corporation in Chicago, and all the results for a one-day horizon are still valid and available upon request.
} 
scenario is calculated using equation (4.2). Each theoretical price scenario corresponds to one theoretical profit $\&$ loss scenario. The projected VaR estimates are the quantiles of the simulated profit \& loss scenarios. Then, we compare actual profits \& losses with projected VaR estimates. In Panel A of Table 5 we summarize the daily exceedances over $95 \%, 97.5 \%, 99 \%$, and $99.5 \%$ for both a long and a short positions. Most of the Kupiec's test (1995) results show that one could not reject the models proposed for risk measures calculation, especially for short positions.

Table 5. Backtesting and coverage. * and ** denote statistic significant for the Kupiec's test at the 5\% and $1 \%$ level respectively.

\begin{tabular}{lrr}
\hline & Brent Oil & WTI \\
\hline Panel A: Exceedances & & $5.35 \%$ \\
VaR95long & $5.96 \% *$ & $4.44 \%$ \\
VaR95short & $5.45 \%$ & $3.37 \% * *$ \\
VaR975long & $3.23 \% *$ & $2.08 \%$ \\
VaR975short & $2.61 \%$ & $1.66 \% * *$ \\
VaR99long & $1.83 \% * *$ & $0.97 \%$ \\
VaR99short & $1.18 \%$ & $1.03 \% * *$ \\
VaR995long & $1.08 \% * *$ & $0.56 \%$ \\
VaR995short & $0.72 \%$ & $5.51 \%$ \\
\hline Panel B: Coverage & & $5.95 \%$ \\
CoverLong & $5.17 \%$ & $9.99 \%$ \\
CoverShort & $5.59 \%$ & $11.35 \%$ \\
Aug-9-2011: Front Contract & & $8.92 \%$ \\
CoverLong & $9.86 \%$ & $8.19 \%$ \\
CoverShort & & $8.91 \%$ \\
Aug-9-2011: One-year Contract & $7.29 \%$ & $7.90 \%$ \\
CoverLong & & \\
CoverShort & &
\end{tabular}

It is interesting to investigate how the models perform in a commercial environment, such as in margin requirements calculation. As the practice of some clearing houses, we define the margin requirements as the weighted sum of expected shortfall at $99.00 \%$ and $99.50 \%$ levels

$$
\text { Margin @0.75ES } S_{99 \%}+0.25 E S_{99.5 \%} .
$$

We are interested in the magnitude of coverage the models produce, since it indicates the margin requirements that futures contract holders will have to supply. The coverage is calculated as a percentage of the positions market value. Coverage varies greatly between contracts and between days so we examine the coverage distributions. Figure 4 and 5 show histograms of the estimated coverage. Summary statistics of the coverage are in Panel B of Table 5. The average coverage of long and short positions for all the commodities are slightly higher than 5\%, and short contracts have higher margin requirements than long positions.
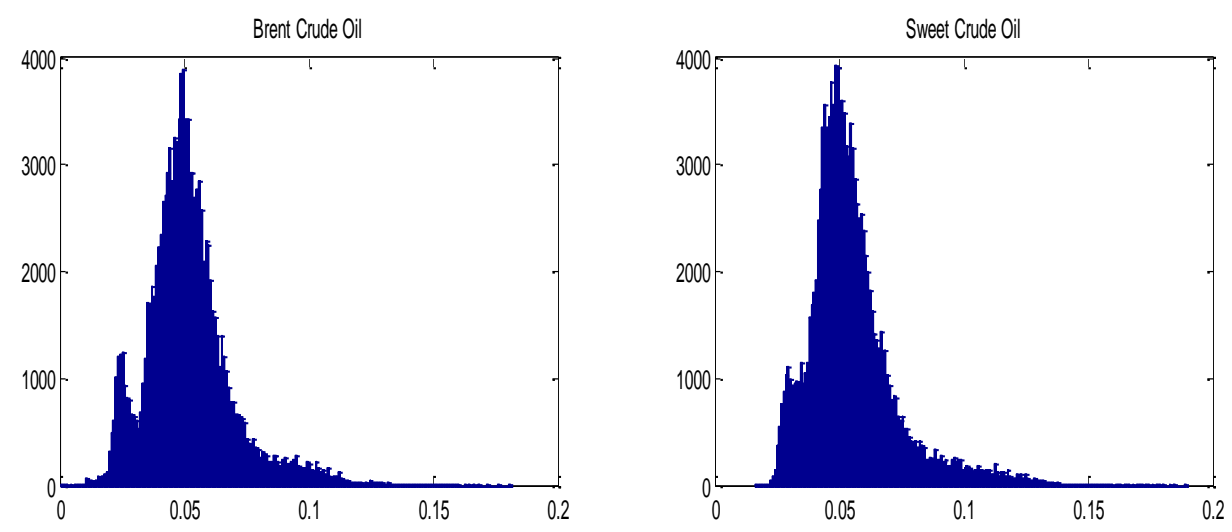

Figure 4. Coverage - Long Contract 



Figure 5. Coverage - Short Contract

In Panel B of Table 5, we also report the coverage of the front and 12.closest long and short contracts on August 9, 2011 for both of the commodities. On August 8, 2011, SPX 500 moves down by $6.90 \%$ because of fears of contagion of the European sovereign debt crisis to Spain and Italy. The coverage of futures contracts increases slightly to the sharp market movement.

\section{Conclusion}

We present the crucial empirical fact of energy commodity futures prices that a successful model must account for: the Samuelson effect. We then apply Schwartz and Smith's model (2000) to account for Brent crude oil futures price dynamics and sweet crude oil futures price dynamics. Our estimation and backtesting results show that the two models provide satisfactory risk measures for the listed energy commodity futures contracts.

There might be several directions for future research. First, it might be interesting to allow non-constant volatilities of shocks of $\eta_{n}$ in our setting and take account of some stylized facts commonly observed in finance data, such as volatility clustering and fat tails as in Guo (2017a, 2017b). Second, to simply our simulation we fixed parameter $\kappa$ and obviously this simplification could be relaxed. Third, we only consider the US data, and it is interesting to consider data from other countries, especially from the emerging countries. Finally, to facilitate practical application, it would be helpful to discuss the finite sample performance as in Shintani and Guo (2016). These extensions are left for future research.

\section{References}

Cabedo, J., \& Moya, I. (2003). Estimating oil price 'Value at Risk' using the historical simulation approach. Energy Economics, 25, 239-253. https://doi.org/10.1016/S0140-9883(02)00111-1

Carmona, R., \& Coulon, M. (2014). A survey of commodity markets and structural models for electricity prices. in F.E. Benth (eds.), Quantitative Energy Finance: Modeling, Pricing, and Hedging in Energy and Commodity Markets, New York: Springer. https://doi.org/10.1007/978-1-4614-7248-3_2

Cortazar, G., \& Schwartz, E. (2003). Implementing a stochastic model for oil futures prices. Energy Economics, 25, 215-238. https://doi.org/10.1016/S0140-9883(02)00096-8

Costello, A., Asem, E., \& Gardner, E. (2008). Comparison of historical simulated VaR: evidence from oil prices. Energy Economics, 30, 2154-2166. https://doi.org/10.1016/j.eneco.2008.01.011

Duffie, D., \& Pan, J. (1997). An overview of Value at Risk," Journal of Derivatives, 4, 7-49.

Fianu, E., \& Grossi, L. (2015). Estimation of risk measures on electricity markets with fat-tailed distributions. Journal of Energy Markets, 8, 29-54. https://doi.org/10.21314/JEM.2015.121

Guo, Z. (2017a). Empirical performance of GARCH models with heavy-tailed innovations," mimeo.

Guo, Z. (2017b). A Stochastic Factor Model for Risk Management of Commodity Derivatives. Proceedings of the 7th Economic and Finance Conference, 2017, 26-42. https://doi.org/10.20472/EFC.2017.007.004

Hung, J., Lee, M., \& Liu, H. (2008). Estimation of value-at-risk for energy commodities via fat-tailed GARCH models. Energy Economics, 30, 1173-1191. https://doi.org/10.1016/j.eneco.2007.11.004 
Kang, S. H., \& Yoon, S. M. (2013). Modeling and forecasting the volatility of petroleum futures prices. Energy Economics, 36, 354-362. https://doi.org/10.1016/j.eneco.2012.09.010

Krehbiel, T., \& Adkins, L. (2005). Price risk in the NYMEX energy complex: an extreme value approach. Journal of Futures Markets, 25, 309-337. https://doi.org/10.1002/fut.20150

Kupiec, P. H. (1995). Techniques for verifying the accuracy of risk measurement models. Journal of Derivatives, 3, 73-84. https://doi.org/10.3905/jod.1995.407942

Marimoutou, V., Raggad, B., \& Trabelsi, A. (2009). Extreme value theory and value at risk: application to oil markets. Energy Economics, 31, 519-530. https://doi.org/10.1016/j.eneco.2009.02.005

Mirantes, A., Poblacion, J., \& Serna, G. (2012). The stochastic seasonal behavior of natural gas prices. European Financial Management, 18, 410-443. https://doi.org/10.1111/j.1468-036X.2009.00533.x

Pirrong, C. (2011), Commodity Price Dynamics: A Structural Approach, Cambridge University Press. https://doi.org/10.1017/CBO9781139018142

Samuelson, P. (1965). Proof that properly anticipated prices fluctuate randomly. Industrial Management Review, 6, 41-49.

Schwartz, E. (1997). The stochastic behavior of commodity prices: implications for valuation and hedging. Journal of Finance, 52, 923-973. https://doi.org/10.1111/j.1540-6261.1997.tb02721.x

Schwartz, E., \& Smith, J. (2000). Short-term variations and long-term dynamics in commodity prices. Management Science, 46, 893-911. https://doi.org/10.1287/mnsc.46.7.893.12034

Shintani, M., \& Guo, Z. (2016). Improving the finite sample performance of autoregression estimators in dynamic factor models: a bootstrap approach. Econometric Reviews, forthcoming.

Sorensen, C. (2002). Modeling seasonality in agricultural commodity futures. Journal of Futures Markets, 22, 393-426. https://doi.org/10.1002/fut.10017

Youssef, M., Belkacem, L., \& Mokni, K. (2015). Value-at-Risk estimation of energy commodities: A long-memory GARCH-EVT approach. Energy Economics, 51, 99-110. https://doi.org/10.1016/j.eneco.2015.06.010

\section{Copyrights}

Copyright for this article is retained by the author(s), with first publication rights granted to the journal.

This is an open-access article distributed under the terms and conditions of the Creative Commons Attribution license (http://creativecommons.org/licenses/by/4.0/). 